\title{
OPEN Insights into antioxidant activities and anti-skin-aging potential of callus extract from Centella asiatica (L.)
}

\author{
Visarut Buranasudja ${ }^{1}$, Dolly Rani ${ }^{2}$, Ashwini Malla ${ }^{2,3}$, Khwanlada Kobtrakul $^{4}$ \& \\ Sornkanok Vimolmangkang ${ }^{2,5}$
}

Formation of oxidative stress in dermal fibroblasts plays crucial roles in aging processes of skin. The use of phytochemicals that can promote capacity of fibroblasts to combat oxidative stress is an attractive strategy to prevent skin aging and promote skin beauty. Centella asiatica has been used to treat multitude of diseases for centuries. Previous investigations demonstrated that extracts from C. asiatica have a broad range of beneficial activities through their antioxidant activity. Hence, the extract from this medicinal plant could be a great candidate for anti-skin-aging agent. Callus culture offers a powerful platform for sustainable, rapid and large-scale production of phytochemicals to serve extensive demands of pharmaceutical and cosmeceutical industries. Here, we demonstrated the application of callus culture of Centella asiatica to produce bioactive metabolites. The $50 \%$ ethanolic extract of callus culture has distinctive features of chemical compositions and biological profiles. Information from HPTLC-DPPH and HPLC analysis suggested that the callus extract comprises distinctive antioxidant compounds, compared with those isolated from authentic plant. Moreover, results from cell culture experiment demonstrated that callus extract possesses promising antioxidant and anti-skin-aging activities. Pre-treatment with callus extract attenuated $\mathrm{H}_{2} \mathrm{O}_{2}$-induced-cytotoxicity on human dermal fibroblasts. The results from RT-qPCR clearly suggested that the upregulation of cellular antioxidant enzymes appeared to be major contributor for the protective effects of callus extract against oxidative stress. Moreover, supplementation with callus extract inhibited induction of matrix metalloprotease-9 following $\mathrm{H}_{2} \mathrm{O}_{2}$ exposure, suggesting its potential anti-skin-aging activity. Our results demonstrate the potential utility of $C$. asiatica callus extract as anti-skin-aging agent in cosmeceutical preparations.

Oxidative stress is a cellular phenomenon caused by a redox imbalance between accumulation of reactive oxygen species (ROS) and capacity of cells to detoxify these harmful agents. The excessive induction of oxidative stress is one of the major driving forces of several pathological condition, including aging processes of skin ${ }^{1}$. Fibroblasts in dermal layer of human skin is the principal target of oxidative stress ${ }^{2}$. Induction of oxidative stress in fibroblasts following exposure to external inducers e.g. ultraviolet radiation ${ }^{3}$, tobacco smoke $^{4}$, and air pollutants ${ }^{5}$, causes a reduction in biosynthesis of collagen as well as a promotion of degradation of collagen. This aberrant homeostasis of collagen weakens structural integrity and mechanical properties of dermal skin, which eventually resulting in the emergence of aging characteristics, e.g. formation of wrinkle and loss of skin elasticity ${ }^{6}$. Hence, the use of compounds or extracts that can enhance the capacity of fibroblasts to neutralize the oxidative stress would be an attractive approach for preventing age-related skin disorders.

\footnotetext{
${ }^{1}$ Department of Pharmacology and Physiology, Faculty of Pharmaceutical Sciences, Chulalongkorn University, Bangkok 10330, Thailand. '2Department of Pharmacognosy and Pharmaceutical Botany, Faculty of Pharmaceutical Sciences, Chulalongkorn University, 254 Phayathai Road, Patumwan, Bangkok 10330, Thailand. ${ }^{3}$ Research Unit for Plant-Produced Pharmaceuticals, Faculty of Pharmaceutical Sciences, Chulalongkorn University, Bangkok 10330, Thailand. ${ }^{4}$ Graduate Program in Pharmaceutical Science and Technology, Faculty of Pharmaceutical Sciences, Chulalongkorn University, Bangkok 10330, Thailand. ${ }^{5}$ Research Unit for Natural Product Biotechnology, Faculty of Pharmaceutical Sciences, Chulalongkorn University, Bangkok 10330, Thailand. ${ }^{\square}$ email: sornkanok.v@ pharm.chula.ac.th
} 
Centella asiatica $(L$.$) is a medicinal herb with high economic value. This plant has been traditionally used for$ treatment of variety diseases in Chinese and Ayurvedic medicines for centuries. The major bioactive metabolites for C. asiatica are centelloids, including asiaticoside, madecassoside, asiatic acid and madecassic acid. These centelloids have been widely used as important biomarker for C. asiatica. Extracts from C. asiatica demonstrates a broad range of pharmacological effects through their antioxidant activities in several preclinical models. Treatment with water extract of $C$. asiatica prevented mitochondrial dysfunctions of isolated neurons through an attenuation of oxidative stress ${ }^{8}$. Ethanolic extract of $C$. asiatica decreased oxidative stress via an enhanced activities of cellular antioxidant enzymes in Parkinson's model of mice ${ }^{9}$. Oral administration of water extract of C. asiatica suppressed lipid peroxidation in an in vivo model of hyperlipidemia ${ }^{10}$. Supplementation of standardized extract of $C$. asiatica inhibited rotenone-induced-hepatotoxicity by inhibition of lipid peroxidation in $v_{i v o}{ }^{11}$. Altogether, extract from C. asiatica has a potential therapeutic utility on oxidative stress-related-disorders, including skin aging.

Naturally grown plant serves as source for secondary metabolites which can be used in cosmeceutical and pharmaceutical industries. However, the major limitations for production of compounds from wild natural plant are the dependence of geographical, seasonal and environmental factors. In addition, further drawbacks for extraction and purification of secondary metabolites from intact plants include complex and time-consuming process; and low concentration of bioactive compounds ${ }^{12}$. To overcome these obstacles, in vitro callus culture has been proposed to be an alternative procedure to efficiently produce bioactive metabolites. This in vitro method offers a manufacturing system which ensures the continuous supply of compounds with uniform quality and high yields. With this approach, cells of any plants, even rare or endangered species, can be easily manipulated and maintained to produce compounds of interest. The active compounds can be produced independently of external factors. Moreover, plant cell culture uses aseptic technique so it will not be threatened by micro-organisms or pests ${ }^{13}$. The maintenance of aseptic conditions is essential for successful tissue culture procedures ${ }^{14}$. Taken together, plant cell culture represents an attractive platform for mass production of phytochemicals.

In this present study, we demonstrated the application of callus culture of $C$. asiatica to produce bioactive metabolites. The major goals of this study are (1) to evaluate the antioxidant capacities of callus extracts; (2) to investigate the beneficial activities of extracts against oxidative stress in human dermal fibroblasts. Data from our study will provide an invaluable insight into potential application of C. asiatica callus extract in anti-aging cosmeceutical products.

\section{Material and methods}

Chemical and reagents. Asiaticoside (98\%; Cat no. 43191), asiatic acid (97\%; Cat no. A2612), madecassoside (95\%; Cat no. M6949), madecassic acid (90\%; Cat no. PHL80229), kaempferol (97 \%; Cat no. 60010), quercetin (95\%; Cat no. Q4951), rutin (95\%; Cat no. R5143), polyethylene glycol (PEG; Cat no. 95904), 2-aminoethyl diphenylborinate (Cat no. D9754), sucrose (Cat no. 1076535000) hydrogen peroxide $\left(\mathrm{H}_{2} \mathrm{O}_{2}\right.$; Cat no. 1072090500), 3-(4,5-dimethylthiazol-2-yl)-2,5-diphenyltetrazolium bromide (MTT; Cat no. M2128), 2,2-diphenyl-1-picrylhydrazyl (DPPH; Cat no. 300267), adenosine 5'-triphosphate (ATP) disodium salt hydrate (Cat no. A2383), $p$-anisaldehyde (Cat no. A88107), dimethyl sulfoxide (DMSO; Cat no. 102952), dichloromethane (Cat no. DX0835), ethyl acetate (Cat no. 107048), and HPTLC silica gel $60 \mathrm{~F}_{254}$ (Cat no. 105642) were purchased from MilliporeSigma (Burlington, MA, USA). HPLC-grade acetonitrile (Cat no. 10754361), ethanol (Cat no. 10538071), acetic acid (Cat no. 14650388) and methanol (Cat no. 10675112) were obtained from J.T. baker (Phillipsburg, NJ, USA). Cell culture media and supplements (minimum essential medium (MEM), fetal bovine serum (FBS), pyruvate, and penicillin/streptomycin) were purchased from Thermo Fisher Scientific (Waltham, MA, USA). All other chemicals in this study were analytical grade. Murashige and Skoog medium (MS; Cat no. M519), 1-naphthaleneacetic acid (Cat no. N605), 6-benzylaminopurine (Cat no. B800) and Agargellan ${ }^{\mathrm{TM}}$ (Cat no. A133) were obtained from Phytotechnology Labs (Lenexa, KS, USA).

Plant material. The explants were obtained from in vitro germinated C. asiatica seedlings. C. asiatica is a commercially available plant and it is grown at the garden of Faculty of Pharmaceutical Sciences, Chulalongkorn University, Thailand (Latitude- $13.7440^{\circ} \mathrm{N}$ and longitude- $100.5307^{\circ} \mathrm{E}$ ). Experimental research on plants complies with relevant institutional, national, and international guidelines and legislation. The seed of the plant used in the study was collected under the permission of the Department of Pharmacognosy and Pharmaceutical Botany, Faculty of Pharmaceutical Sciences, Chulalongkorn University, Thailand. The plant was identical to a voucher specimen (herbarium number 010018) deposited at Museum of Natural Medicines, Chulalongkorn University, Thailand. To remove dust particles, collected seeds were washed with detergent for $10 \mathrm{~min}$. The prewashed seeds were sterilized with $70 \%$ ethanol for $1 \mathrm{~min}$, followed by $20 \%$ commercial bleach solution for 10 min. All subsequent steps were performed under a laminar flow cabinet. The seeds were washed five times with sterile distilled water to remove all traces of sterilant. The sterilized seeds were then inoculated on Murashige and Skoog medium, supplemented with $0.5 \%$ Agargellan ${ }^{\mathrm{TM}}$ plus $3 \%$ sucrose, and kept in dark at $23 \pm 2{ }^{\circ} \mathrm{C}$.

Callus induction. Callus was obtained from in vitro germinated C. asiatica seedling using the protocol reported by Loc and An with slight modifications ${ }^{15}$. Briefly, about $1 \mathrm{~cm}$ long stolon explants of 15 days old seedling of $C$. asiatica were cut and inoculated on MS medium ( $\mathrm{pH}$ 5.7) supplemented with $1 \mathrm{mg} / \mathrm{L}$ of 1-naphthaleneacetic acid, $1 \mathrm{mg} / \mathrm{L}$ of 6-benzylaminopurine, $0.5 \%$ Agargellan $^{\mathrm{TM}}$ and $3 \%$ sucrose. The cultures were incubated at $23 \pm 2{ }^{\circ} \mathrm{C}$ under $16 \mathrm{~h}$ photoperiod and $30 \mu \mathrm{E} \mathrm{m}^{-2} \mathrm{~s}^{-1}$ irradiance provided by cool white fluorescent tubes. Callus were routinely sub-cultured onto the same medium every 30 days. 
Preparation of extracts and standards. About $100 \mathrm{mg}$ of ground callus and authentic plant samples were individually mixed with $1 \mathrm{~mL}$ of methanol, $95 \%$ ethanol, $75 \%$ ethanol or $50 \%$ ethanol (v/v); extracted for $30 \mathrm{~min}$ by using sonication at $25^{\circ} \mathrm{C}$; and then filtered through Whatman Grade 42 paper (Whatman plc; Maidstone, UK). The filtrate was then used for HPTLC and HPLC analysis.

For standards (asiaticoside, asiatic acid, madecassoside, madecassic acid, kaempferol, quercetin and rutin), the working solutions were prepared in methanol at final concentration of $1 \mathrm{mg} / \mathrm{mL}$ and filtered for further use.

High-performance thin-layer chromatography (HPTLC). The compounds in extracts were separated by using HPTLC technique. Briefly, $5 \mu \mathrm{L} /$ band of the Centella extracts and $4 \mu \mathrm{L} / \mathrm{band}$ of the standards were applied on the Merck silica gel $60 \mathrm{~F}_{254}$ glass HPTLC plates $(20 \times 10 \mathrm{~cm})$ by a semi-automatic sampler Linomat 5 (Camag; Muttenz, Switzerland) using $8 \mathrm{~mm}$ bands, $11.4 \mathrm{~mm}$ apart, $8 \mathrm{~mm}$ from the lower edge, and $20 \mathrm{~mm}$ from the left plate edge. The plates were developed in the chamber saturation containing mobile phases. For separation of triterpenoids, the mobile phase was dichloromethane: methanol: water $(14: 6: 1, \mathrm{~V} / \mathrm{V} / \mathrm{V})^{16}$. For separation of flavonoids, ethyl acetate: methanol: water $(100: 25: 10, \mathrm{~V} / \mathrm{V} / \mathrm{V})$ was used as mobile phase. The development was done with a migration distance of $70 \mathrm{~mm}$ using an automatic development chamber ADC2 (Camag; Muttenz, Switzerland). For observation of triterpenoids, the plate was dipped with sulfuric reagent using Chromatogram Immersion Device III (Camag; Muttenz, Switzerland) and then heated at $100{ }^{\circ} \mathrm{C}$ for 3 min on the TLC Plate Heater (Camag; Muttenz,Switzerland). The derivatized plates were visualized under white light using visualizer 2 (Camag; Muttenz, Switzerland). For detection of flavonoids, the chromatogram was heated at $110^{\circ} \mathrm{C}$ for $3 \mathrm{~min}$ and then was dipped in NP/PEG reagent. The derivatized plates were visualized under UV light at $366 \mathrm{~nm}$ using visualizer 2 (Camag; Muttenz, Switzerland).

HPTLC-DPPH bioautographic assay. In order to estimate the antioxidant activity of tested samples, HPTLC-DPPH was performed as a screening assay. After development, the HPTLC plates were immersed with $0.02 \%$ DPPH-methanol solution and incubated in dark for $2 \mathrm{~h}^{17}$. The chromatogram was then examined under white light. Generated bands with yellowish color on the purple backgrounds were considered as compounds with antioxidant activities.

DPPH assay. The radical scavenging activities of tested extracts were evaluated by traditional DPPH assay ${ }^{18}$. Briefly, $100 \mu \mathrm{L}$ of DPPH solution $(0.008 \% \mathrm{w} / \mathrm{v}$ DPPH in methanol) was mixed with $100 \mu \mathrm{L}$ of varying concentrations of callus extract in a 96-well microplate and incubated at $25^{\circ} \mathrm{C}$ for $30 \mathrm{~min}$. After incubation, the absorbance was recorded at $517 \mathrm{~nm}$ using CLARIOStar microplate reader (BMG Labtech; Ortenberg, Germany). 100\% methanol was used as a control.

The percentage of radical scavenging activity (\%RSA) of sample was calculated using the following formula:

$$
\% R S A=\frac{\left(\text { OD } 517_{\text {Control }}-\text { OD } 517_{\text {sample }}\right) \times 100}{\text { OD } 517_{\text {Control }}}
$$

OD $517_{\text {Control }}=$ Optical density at $517 \mathrm{~nm}$ of $100 \%$ methanol; OD $517_{\text {sample }}=$ Optical density at $517 \mathrm{~nm}$ of samples.

The concentration of extracts that resulted in 50\% RSA was estimated from dose-response curve using GraphPad Prism version 9.0 (GraphPad Software).

HPLC analysis. Seven standards, namely, asiaticoside, asiatic acid, madecassoside, madecassic acid, kaempferol, quercetin and rutin, along with the callus extract were used for the analysis. The analysis was performed using a Shimadzu HPLC (LC-20A) connected with a PDA detector (Shimadzu; Kyoto, Japan). A C-18 column $(100 \mathrm{~mm} \times 4.6 \mathrm{~mm}, 5 \mu \mathrm{m}$ particle size, Phenomenex, USA) was used. The HPLC analysis was conducted according to the method of Buraphaka and Putalun ${ }^{19}$. The mobile phase used was a gradient of $1 \%$ acetic acid (A) and acetonitrile (B) at a flow rate of $1 \mathrm{~mL} / \mathrm{min}$ with the following linear gradient HPLC solvent program: solvent B was increased from 0 to $25 \%$ over $20 \mathrm{~min}$ and further increased to $40 \%$ over $35 \mathrm{~min}$, followed by further increase to $65 \%$ till $40 \mathrm{~min}$ and then held at $100 \% \mathrm{~A}$ for $5 \mathrm{~min}$ before returning to the initial state. The column temperature was controlled at $30^{\circ} \mathrm{C}$, and chromatograms were recorded at 210 and $320 \mathrm{~nm}$.

Cell culture. Human foreskin fibroblasts, BJ (ATCC ${ }^{\circ}$ CRL-2522), were obtained from American Type Culture Collection (ATCC; Manassas, VA, USA). The condition for cell culture was followed the standard protocol as described previously ${ }^{20}$. BJ cells were maintained in MEM supplemented with $1 \mathrm{mM}$ pyruvate, $10 \%$ FBS, and $100 \mathrm{U} / \mathrm{mL}$ penicillin and $100 \mu \mathrm{g} / \mathrm{mL}$ streptomycin. The cells were cultured at $37^{\circ} \mathrm{C}$ in a humidified atmosphere with $5 \% \mathrm{CO}_{2}$.

Exposure of $\mathrm{H}_{2} \mathrm{O}_{2}$. $\quad \mathrm{H}_{2} \mathrm{O}_{2}$ was used as an inducing agent for oxidative stress ${ }^{18}$. A solution of $\mathrm{H}_{2} \mathrm{O}_{2}$ was freshly prepared in serum-free MEM prior each experiment. To examine the cytotoxicity of $\mathrm{H}_{2} \mathrm{O}_{2}$, the BJ cells were exposed to $\mathrm{H}_{2} \mathrm{O}_{2}$ at $200 \mu \mathrm{M}$ for $1 \mathrm{~h}$. For a control group, the medium was replaced with a fresh serum-free MEM similar to the $\mathrm{H}_{2} \mathrm{O}_{2}$-treated cells.

Centella extract treatments. The $50 \%$ ethanolic extracts of Centella were dissolved with DMSO to produce a $1 \mathrm{mg} / \mathrm{mL}$ stock solutions. The treatment protocol was slightly modified from our previous in vitro experiments on skin cells ${ }^{21,22}$. To observe the preventive activities of Centella extracts against $\mathrm{H}_{2} \mathrm{O}_{2}$-induced cytotoxicity, BJ cells were pre-treated with the Centella extracts (final concentration, $15-60 \mu \mathrm{g} / \mathrm{mL} ; 0.5 \% \mathrm{DMSO}$ ) for $24 \mathrm{~h}$ 
prior to $\mathrm{H}_{2} \mathrm{O}_{2}$ treatment. Control groups were incubated with an equivalent amount of DMSO (0.5\% DMSO). DMSO at $0.5 \%$ is considered as the non-toxic concentration of DMSO for the BJ cells.

Cell viability assay. The cell viability was determined by using MTT assay ${ }^{23}$. Briefly, BJ cells were seeded into 96-well plates at density of 20,000 cells/well. The cells were cultured for $24 \mathrm{~h}$ at $37^{\circ} \mathrm{C}, 5 \% \mathrm{CO}_{2}$ before exposure to the experimental condition. After indicated treatments, exposure media were aspirated, and the cells were washed with phosphate buffer solution (PBS; $\mathrm{pH}$ 7.4). The washed cells were incubated in dark with MTT solution $(200 \mu \mathrm{L} ; 1 \mathrm{mg} / \mathrm{mL}$ in serum-free MEM). After 3-h incubation, the MTT solution was removed, and the formazan crystals were dissolved with DMSO $(200 \mu \mathrm{L} /$ well $)$. The absorbance of the formazan solution was then measured at $570 \mathrm{~nm}$ using the CLARIOStar microplate reader.

Measurement of an intracellular ATP. The BJ cells were seeded into multiple culture dishes $(60 \mathrm{~mm})$ at a density of 250,000 cells per dish in $4 \mathrm{~mL}$ of the MEM. Cells were cultured for $24 \mathrm{~h}$ at $37{ }^{\circ} \mathrm{C}, 5 \% \mathrm{CO}_{2}$ before exposure to experimental conditions. Following the indicated treatments, treated cells were trypsinized and resuspended with PBS. Levels of intracellular ATP were immediately measured with CellTiter-Glo Luminescent Cell Viability Assay (Promega, Madison, WI, USA; Cat no. G7570) as previously described ${ }^{24}$. Briefly, a cell suspension (50,000 cells in $100 \mu \mathrm{L}$ of PBS) was added into each well of opaque walled, 96-well white microplate. Subsequently, $100 \mu \mathrm{L}$ of the CellTiter-Glo reagent was homogenously mixed with the cell suspension at room temperature to induce cell lysis and start the luminescent reaction. After a 10-min incubation, the luminescent signal was measured using the CLARIOStar microplate reader. The generated luminescent signal is directly proportional to the amount of ATP in the sample. To estimate the intracellular level of ATP, standard curves for each experiment were produced with serial dilutions of ATP solutions $(0-1000 \mu \mathrm{M})$. The amount of ATP in each sample was calculated from the corresponding standard curve and then further transformed to an intracellular concentration using the cell number.

Real time-quantitative polymerase chain reaction (RT-qPCR). After treatments, total RNA was isolated from BJ cells by using GENEzol reagent (Geneaid Biotech Ltd., New Taipei City, Taiwan; Cat no. GZR100) according to manufacturer's protocol. One microgram of extracted RNA was then reverse transcribed into cDNA by using RevertAid First Strand cDNA Synthesis Kit (Thermo Fisher Scientific, Waltham, MA, USA; Cat no. K1621). The RT-qPCR was carried out in CFX96 Touch Real-Time PCR Detection System (Bio-Rad Laboratories, Hercules, CA, USA) with Luna Universal qPCR Master Mix (New England Biolabs, Ipswich, MA, USA; Cat No: M3003L) following the manufacturer's instruction. The expression of interested genes were quantified by using $\Delta \Delta \mathrm{Cq}$ approach with normalization to house-keeping $\beta$-Actin. The conditions for RT-qPCR were modified from previous study by Biagini and colleagues ${ }^{25}$. The PCR conditions, sequences of primer nucleotide (Macrogen, Seoul, South Korea) and analysis of RNA extraction are listed in Supplementary Table S1, S2, and S3 respectively.

Statistical analysis. The unpaired $t$ test and one-way analysis of variance (ANOVA) with Tukey's post hoc were conducted to evaluate statistical differences between means. All means and standard errors of the mean (SEMs) were calculated from three independent experiments. Data were expressed as the mean \pm SEM. Statistical analysis was performed using GraphPad Prism version 9.0.

\section{Results}

Antioxidant activities of Centella extracts. To determine a suitable solvent for extraction process, callus culture and authentic plant of $C$. asiatica were extracted with series of solvents, including methanol, $95 \%$ ethanol, 70\% ethanol, and 50\% ethanol. Due to their abundance and pharmacological activities, asiaticoside, asiatic acid, madecassoside, and madecassic acid are considered to be major active components of C. asiatica ${ }^{7,26}$. To examine whether callus extract (CE) and authentic plant extract (APE) contains these triterpenoids, active compounds in extracts were separated with HPTLC approach. All of four centelloids were observed in APE (Lanes 5-8; Fig. 1A); however, none of them were detected in CE (Lanes 9-12; Fig. 1A). To screen active antioxidants in the extracts, HPTLC plates were further derivatized with DPPH reagent. A stable free radical DPPH is a widely used substrate to evaluate free radical scavenging activities of tested compounds. On HPTLC plates, the compounds generating yellow zones against the purple background were considered as antioxidants. The CE and APE exhibited strong free radical scavenging activities. Interestingly, all of tested triterpenoids did not show antioxidant activities (Fig. 1B; Lanes 1-4). The CE showed significant antioxidant activity in the absence of these standards. These HPTLC-DPPH data suggested that asiaticoside, asiaticoside, asiatic acid, madecassoside, and madecassic acid do not contribute to antioxidant properties of the extracts.

Kaempferol, quercetin, and rutin reported in C. asiatica ${ }^{27,28}$ are flavonoid compounds with antioxidant activities. It was suspected that these compounds may contribute to the antioxidant activity of the extracts. However, the chromatogram on the HPTLC plate demonstrated that these three flavonoids were not presented in any extracts (Fig. 2A). The data from HPTLC-DPPH showed that CE and APE exhibited significant antioxidant activities, as evidenced by a great intensity of yellow spots (Fig. 2B). Moreover, Centella extracts exhibited potent radical scavenging properties without the presence of kaempferol, quercetin and rutin (Fig. 2B). Taken together, these results strongly suggested that antioxidant activities of extracts are not due to these three flavonoids but possibly from other flavonoids.

As demonstrated in Figs. 1B and 2B, it was observed that 70\% and 50\% ethanolic extracts of both authentic plant (Fig. 1B, lanes 7 and 8; Fig. 2B, lanes 6 and 7) and callus (Fig. 1B, lanes 11 and 12; Fig. 2B lanes 10 and 11) have the strongest intensity of bands in HPTLC-DPPH analysis. Hence, $50 \%$ ethanol would be the suitable 


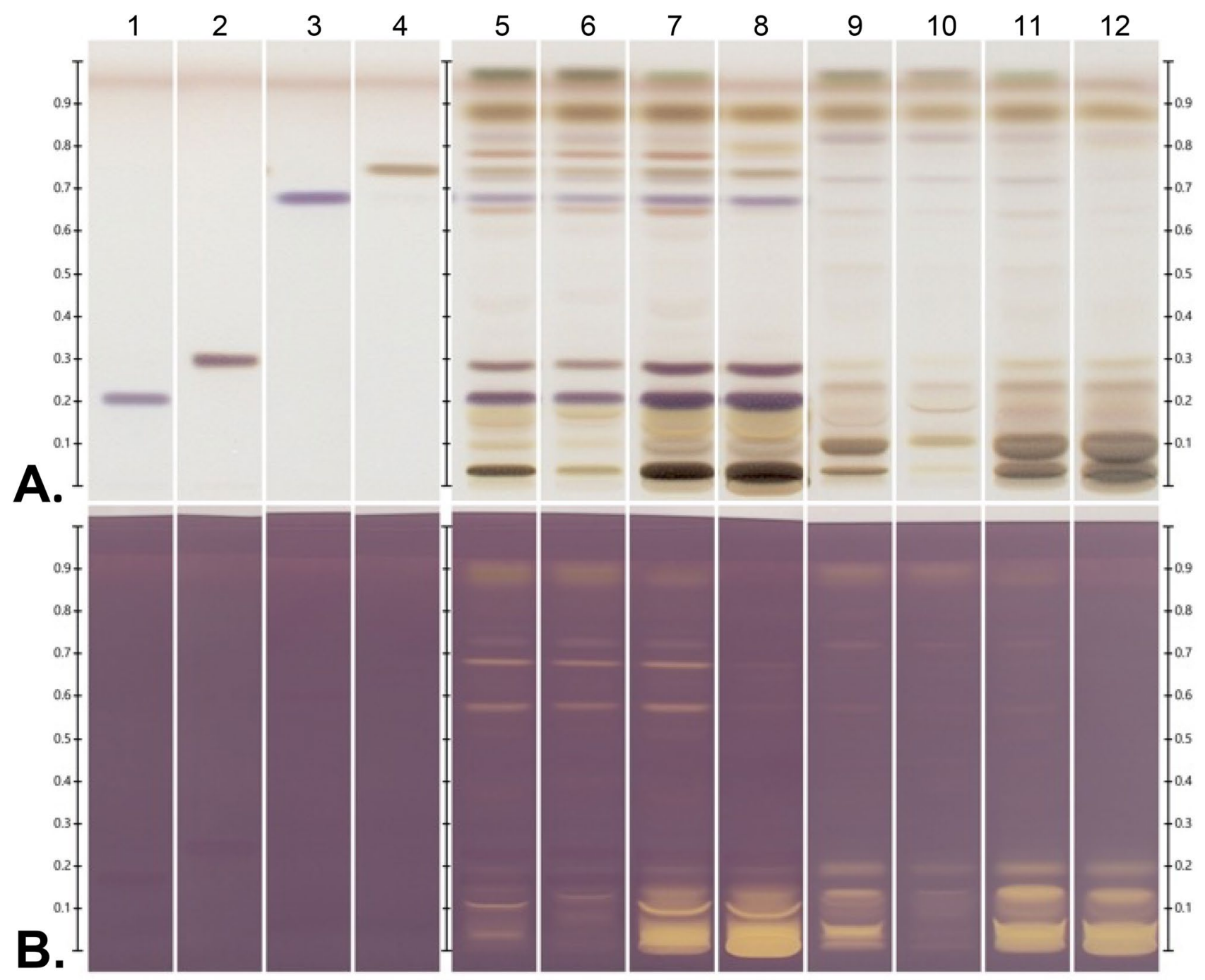

Figure 1. The antioxidant activities of Centella extracts are not due to asiaticoside, asiatic acid, madecassoside and madecassic acid. HPTLC fingerprints of triterpene standards (1, madecassoside; 2 , asiaticoside; 3 madecassic acid; 4, asiatic acid), APE (5, methanol; 6, $95 \%$ ethanol; 7, $70 \%$ ethanol; 8, $50 \%$ ethanol), and CE (9, methanol; 10, $95 \%$ ethanol; 11, $70 \%$ ethanol; 12, $50 \%$ ethanol). (A) The HPTLC plate was derivatized with anisaldehyde sulphuric acid reagent and visualized with white light. (B) The HPTLC plate was dipped with DPPH reagent and visualized with white light.

solvent to be used in extraction of C. asiatica because (1) $50 \%$ ethanolic extracts of callus and authentic plant exhibit high antioxidant activity; (2) the amount of organic solvent is less than $70 \%$ ethanolic extracts; and (3) ethanol is safer than methanol, then it is practical to develop product for cosemeceutical purposes. Hence, 50\% ethanolic extracts of callus and authentic plant were chosen for further experiments of this study.

As shown in Figs. 1 and 2, the antioxidant properties of CE were comparable to APE. We then further evaluate total antioxidant activity of these two 50\%-ethanolic extracts by determination of IC50 of \%RSA with DPPH assay. The IC50 of \%RSA represents the concentration of extracts that is required for $50 \%$ free radical scavenging activity. We exhibited that CE had approximately 2.5 folds greater ability to neutralize free radicals than APE (Supplementary Fig. 1; CE, 98.6 $\pm 1.6 \mu \mathrm{g} / \mathrm{mL}$ vs APE, $243.3 \pm 14.6 \mu \mathrm{g} / \mathrm{mL}$ ). These results suggest that extract from callus culture possesses a strong free radical scavenging ability, which is even greater than from native plant.

HPLC analysis of Centella extracts. HPLC was conducted to analyze and compare chemical compositions in Centella extracts (Fig. 3) and validate the result of HPTLC technique. On comparison with retention time (RT) between standards and extracts, none of CE contained asiaticoside (RT $=30.48 \mathrm{~min}$ ), asiatic acid $(\mathrm{RT}=44.13 \mathrm{~min})$, madecassoside $(\mathrm{RT}=28.35 \mathrm{~min})$, madecassic acid $(\mathrm{RT}=42.21 \mathrm{~min})$, kaempferol $(\mathrm{RT}=37.68 \mathrm{~min})$, quercetin $(\mathrm{RT}=32.68 \mathrm{~min})$, and rutin $(\mathrm{RT}=22.88 \mathrm{~min})$. All the standards were detected in the APE, irrespective of the solvent used for extraction. These HPLC data are consistent with HPTLC results demonstrated in Figs. 1 and 2. Moreover, CE demonstrated different chemical profiles when compared to APE. Hence, the difference in antioxidant capacity between CE vs APE could possibly be due to variation in active components. 


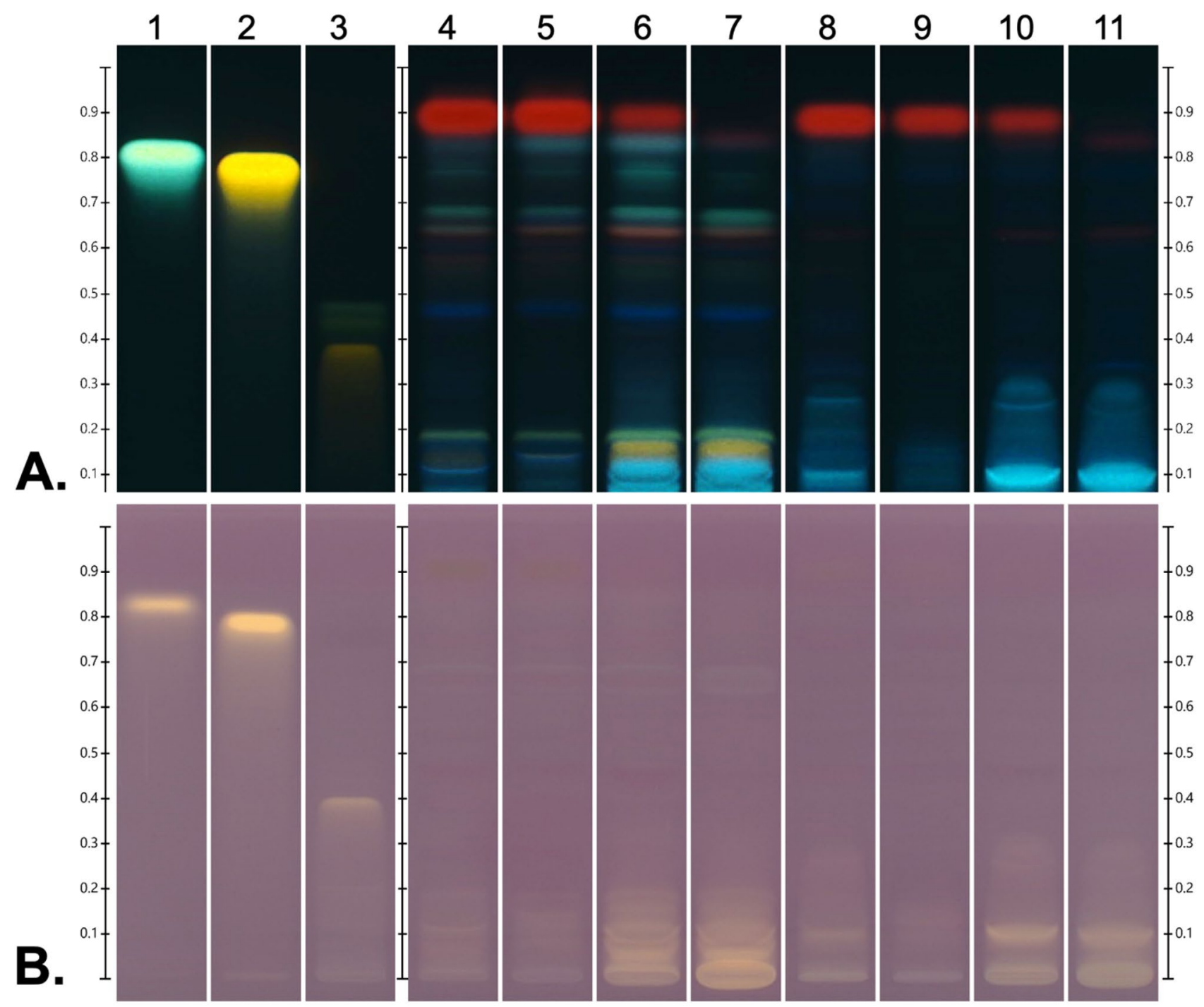

Figure 2. The antioxidant activities of Centella extracts are not due to kaempferol, quercetin and rutin. HPTLC fingerprints of flavonoid standards (1, kaempferol; 2, quercetin; 3, rutin), APE (4, methanol; 5, 95 \% ethanol; 6, $70 \%$ ethanol; 7, $50 \%$ ethanol), and CE (8, methanol; 9, $95 \%$ ethanol; 10, $70 \%$ ethanol; 11, $50 \%$ ethanol). (A) The HPTLC plate derivatized with NP/PEG solution and visualized under UV light at $366 \mathrm{~nm}$. (B) The HPTLC plate was immersed with DPPH reagent and visualized with white light.

Protective effects of Centella extracts against oxidative damage on human fibroblasts. The compounds with antioxidant capacity have been proposed as promising candidate for anti-skin-aging agents ${ }^{29}$. According to cell-free based antioxidant assay, CE and APE were selected to further examine their beneficial activities on human dermal fibroblast BJ cells. Firstly, we evaluated potential toxicity of CE and APE on dermal fibroblasts. The data from MTT assay demonstrated that 24-h exposure of CE or APE, up to $60 \mu \mathrm{g} / \mathrm{mL}$, did not cause toxicity to BJ cells (Fig. 4A, B). Hence, concentrations of CE and APE at 15-60 $\mu \mathrm{g} / \mathrm{mL}$ were chosen for subsequent experiments.

To investigate the preventive effects of $\mathrm{CE}$ and APE against oxidative insults, $\mathrm{BJ}$ cells were pre-treated with $\mathrm{CE}$ or APE at non-toxic concentration for $24 \mathrm{~h}$ prior to $\mathrm{H}_{2} \mathrm{O}_{2}$ treatment. Exposure to $\mathrm{H}_{2} \mathrm{O}_{2}(200 \mu \mathrm{M} ; 1 \mathrm{~h})$ reduced cell viability of BJ cells to approximately $25 \%$ (Fig. $4 \mathrm{C}$ ). Pre-treatment with CE significantly inhibited $\mathrm{H}_{2} \mathrm{O}_{2}$-induced toxicity (Fig. 4C). Interestingly, the protective effects of CE were comparable to APE pre-treatments (Fig. 4D). These data suggested that CE and APE could exert their beneficial effects against $\mathrm{H}_{2} \mathrm{O}_{2}$ on dermal fibroblasts via their antioxidant activities.

The imbalance of cellular bioenergetics due to oxidative stress is closely linked to aging processes of several tissues, including skin ${ }^{30}$. Exposure to $\mathrm{H}_{2} \mathrm{O}_{2}$ caused an immediate depletion of steady-state levels of ATP in dermal fibroblasts (Fig. 4E). In contrast, treatment with non-toxic concentration of CE $(60 \mu \mathrm{g} / \mathrm{mL} ; 24 \mathrm{~h})$ did not alter intracellular levels of ATP, supporting the safety of CE on the selected concentration on BJ cells (Fig. 4E). Interestingly, pre-treatment with CE significantly inhibited reduction of intracellular ATP pool following $\mathrm{H}_{2} \mathrm{O}_{2}$ treatment in dose-dependent fashion (Fig. 4F). The results from these bioenergetics studies were consistent 


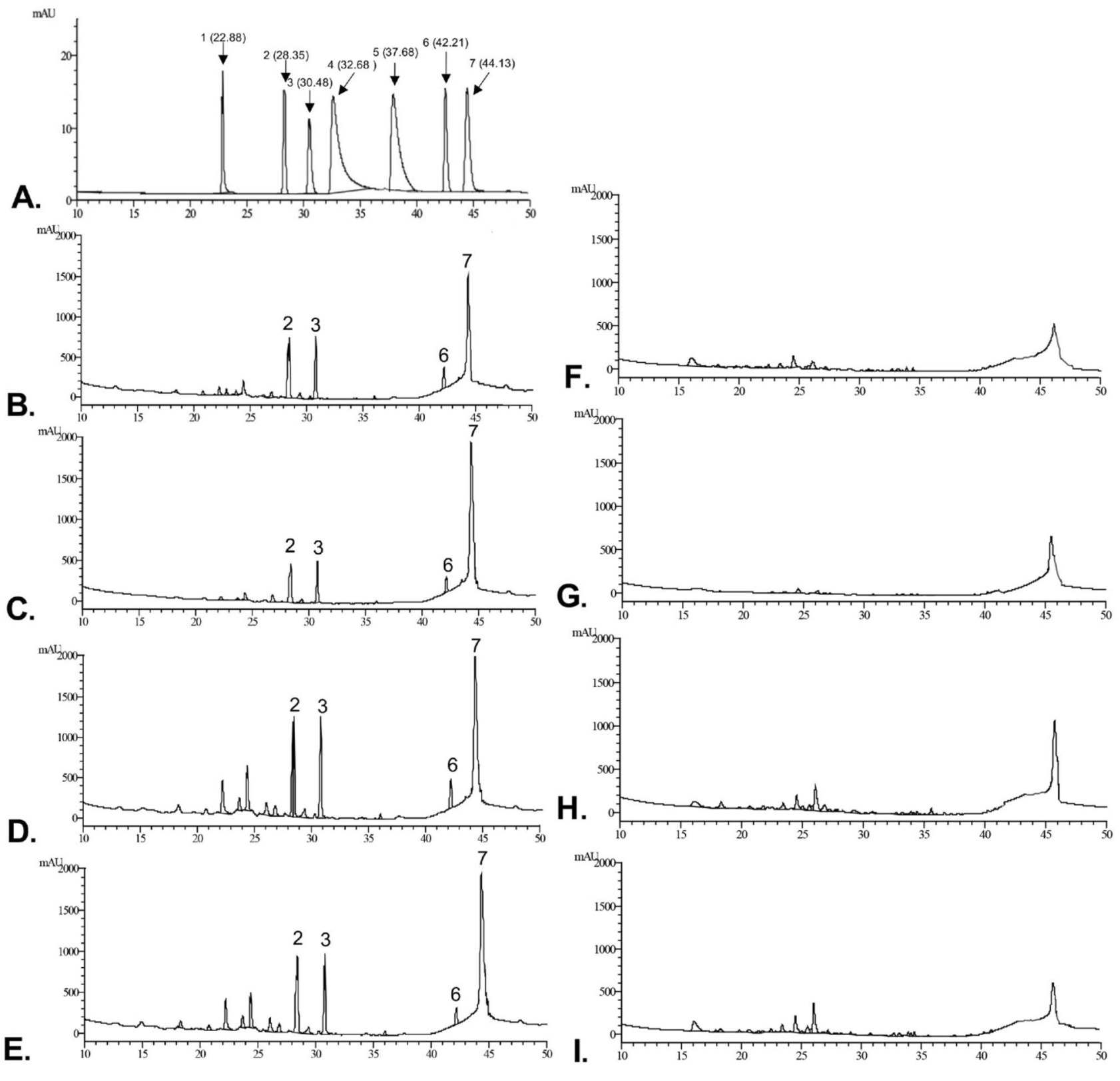

Figure 3. Centella extract from callus culture has unique chemical profiles. HPLC chromatogram of (A) standard solutions of triterpenes and flavonoids (1, rutin; 2, madecassoside; 3, asiaticoside; 4, quercetin; 5, kaempferol; 6, madecassic acid; 7, asiatic acid); (B-E) Authentic plant extract (B, methanol; C, 95\% ethanol; D, 70\% ethanol, E, 50\% ethanol); and (F-I) Callus extract (F, methanol; G, 95\% ethanol; H, 70\% ethanol, I, 50\% ethanol). The retention time (RT) was shown in parenthesis.

with the protective effects of CE against oxidative damage from MTT assay, highlighting the contribution of antioxidant activity of $\mathrm{CE}$ on its protective effect against oxidative insults.

Effects of Centella extracts on expression of antioxidant enzymes. The beneficial effects of CE and APE against oxidative damage as showed in Fig. 4 are possibly due to an induction of capacity of fibroblasts to detoxify reactive oxygen species (ROS). To examine this hypothesis, the mRNA expression of key antioxidant enzymes, including catalase (CAT), glutathione peroxidase 1 (GPx1), superoxide dismutase 1 (SOD1), and superoxide dismutase 2 (SOD2), were measured following 24-h treatments. Our RT-qPCR results demonstrated that CE and APE have different profiles on the induction of antioxidant machinery of fibroblasts; CE induced expression of CAT in dose-dependent fashion (Fig. 5A), while APE enhanced expression of both SOD1 (Fig. 5C) and SOD2 (Fig. 5D). The expression of GPX1 did not alter with either CE or APE treatment (Fig. 5B). These RTqPCR data suggested that an upregulation of cellular antioxidant enzymes is the principal factor for protective effects of CE and APE.

We also observed the effects of Centella extracts on expression of antioxidant enzymes after $\mathrm{H}_{2} \mathrm{O}_{2}$ treatment. Exposure to $\mathrm{H}_{2} \mathrm{O}_{2}$ leaded to dramatic decrease in GPx1 (Fig. 5B) and SOD1 (Fig. 5C); and significant increase in 

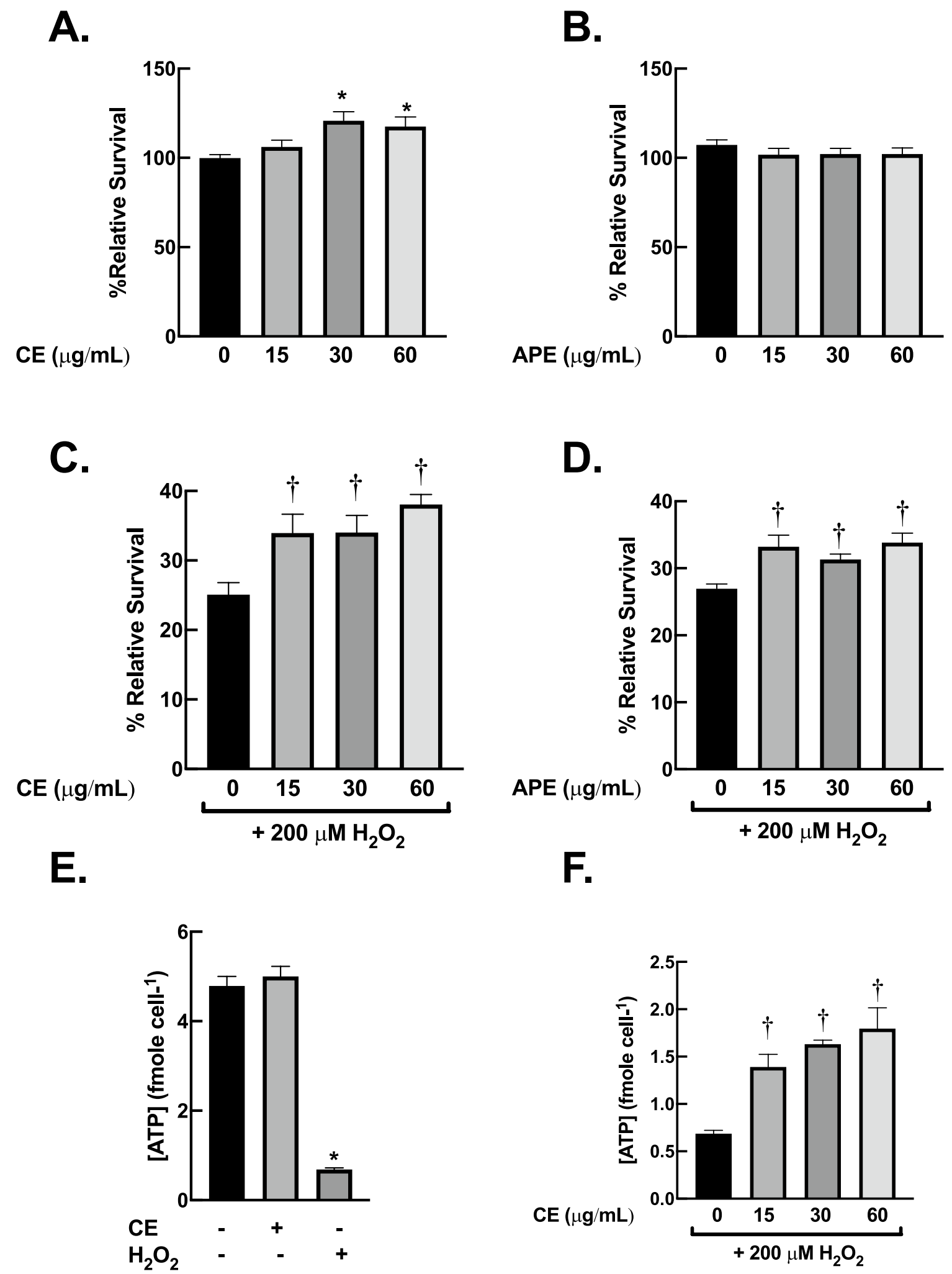

Figure 4. Centella extracts prevent $\mathrm{H}_{2} \mathrm{O}_{2}$-induced cytotoxicity in dermal fibroblasts. (A) and (B) CE and APE at $15-60 \mu \mathrm{g} / \mathrm{mL}$ did not cause toxicity in dermal fibroblasts. BJ cells were incubated with CE or APE $(15-60 \mu \mathrm{g} /$ $\mathrm{mL}$ ) for $24 \mathrm{~h}$. (C) and (D) CE and APE inhibit oxidative damage from $\mathrm{H}_{2} \mathrm{O}_{2}$ exposure. BJ cells were preincubated with CE or APE $(15-60 \mu \mathrm{g} / \mathrm{mL})$ for $24 \mathrm{~h}$ then exposed to $\mathrm{H}_{2} \mathrm{O}_{2}(200 \mu \mathrm{M})$ for $1 \mathrm{~h}$. The cell viability was evaluated with MTT assay immediately after the treatments. (E) and (F) CE inhibit depletion of intracellular ATP following $\mathrm{H}_{2} \mathrm{O}_{2}$ exposure. The protocol for treatment was as (A) and (C). The amounts of ATP were

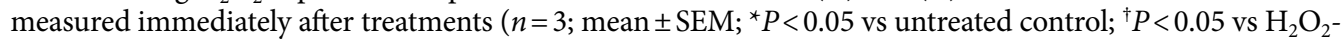
treated cells). 
A.

B.
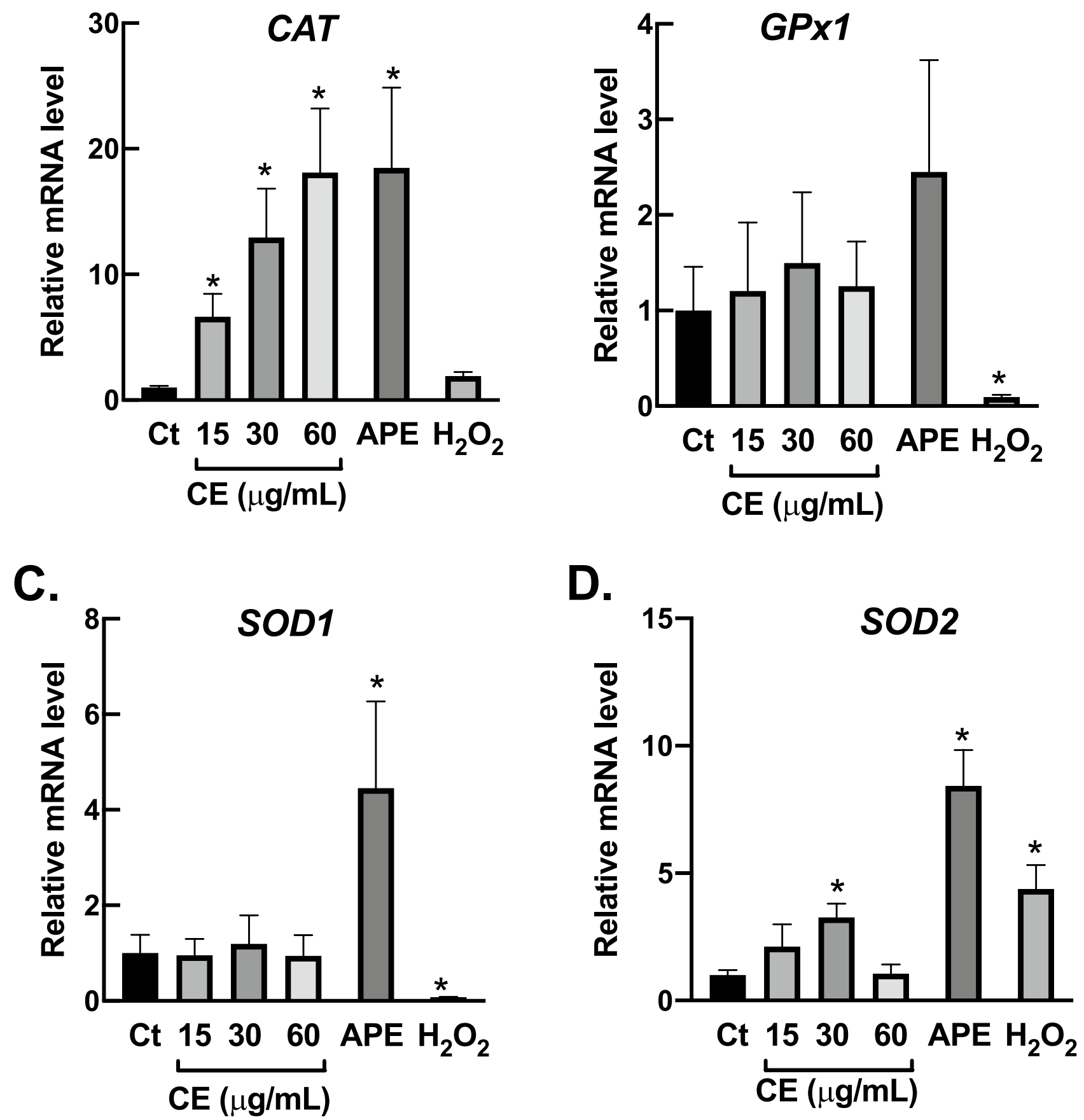

Figure 5. Centella extracts elevate transcription of antioxidant enzymes. (A-D) CE promoted CAT expression, while APE enhanced SOD1 and SOD2 expression. BJ cells were incubated with CE $(15-60 \mu \mathrm{g} / \mathrm{mL} ; 24 \mathrm{~h})$ or APE $(60 \mu \mathrm{g} / \mathrm{mL} ; 24 \mathrm{~h})$ or $\mathrm{H}_{2} \mathrm{O}_{2}(200 \mu \mathrm{M} ; 1 \mathrm{~h})$. The expressions of antioxidant machineries, including CAT, GPx1, SOD1, and SOD2, were determined with RT-PCR following treatments $\left(n=3\right.$; mean $\pm S E M ;{ }^{\star} P<0.05$ vs untreated control).

SOD2 (Fig. 5D). The increase of SOD2 expression is possibly due to adaptive mechanism of fibroblasts following $\mathrm{H}_{2} \mathrm{O}_{2}$ treatment. This phenomenon has been reported in several models of aged fibroblasts ${ }^{31-33}$. Again, $\mathrm{CE}$ and APE demonstrated distinctive effects on induction of antioxidant enzymes following $\mathrm{H}_{2} \mathrm{O}_{2}$ exposure. Pre-treatment with CE induced CAT (Fig. 6A), GPx1 (Fig. 6B) and SOD1 expression (Fig. 6C), whereas APE upregulated $S O D 2$ expression following 1-h exposure to $\mathrm{H}_{2} \mathrm{O}_{2}$ (Fig. 6D). Altogether, these results clearly exhibited that Centella extracts could prevent $\mathrm{H}_{2} \mathrm{O}_{2}$ cytotoxicity by an enhanced capacity of fibroblasts to remove deleterious ROS. 

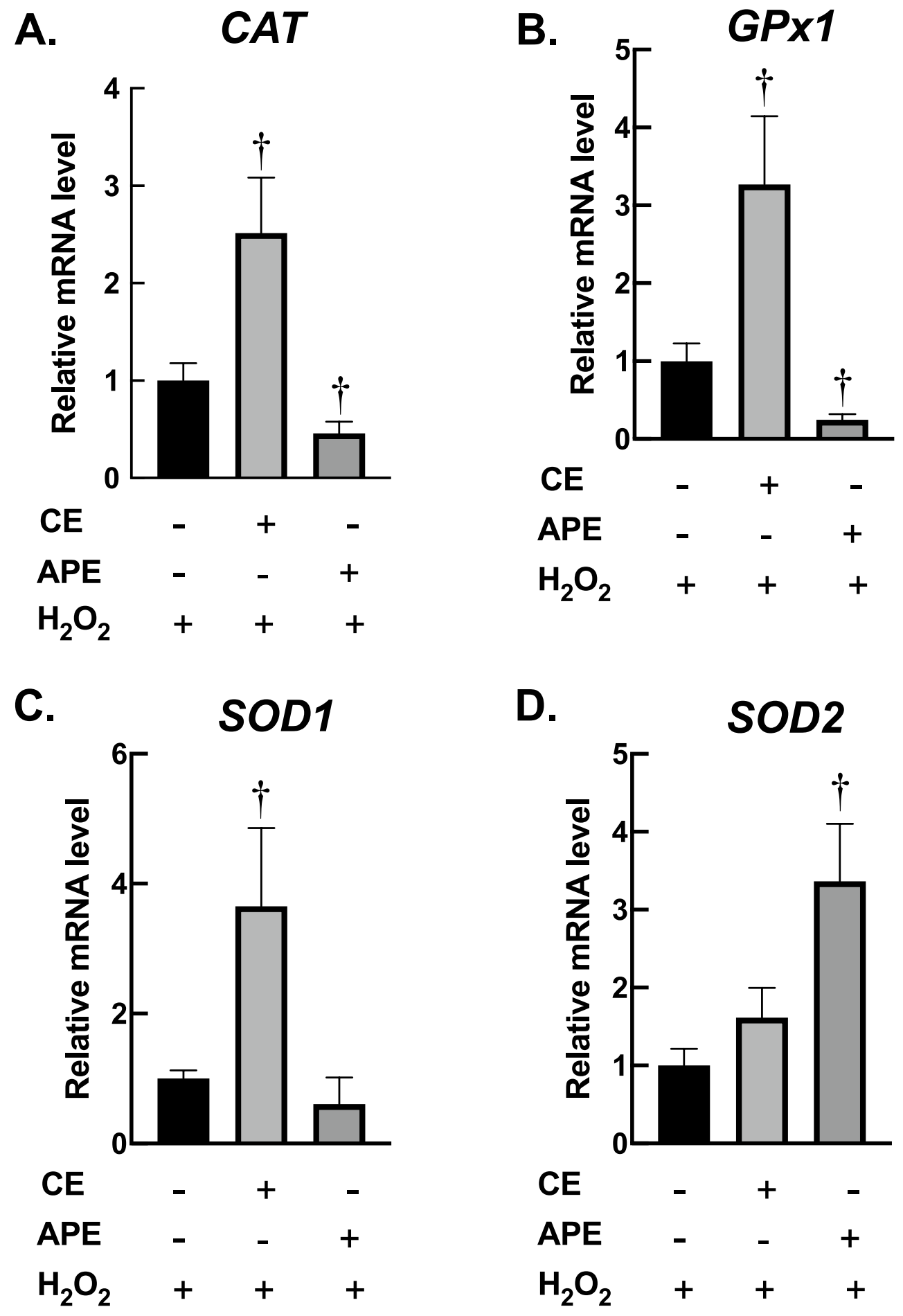

D.
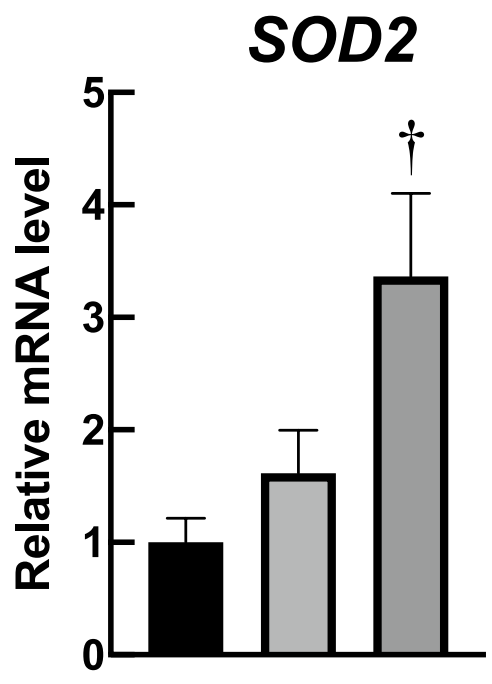

CE

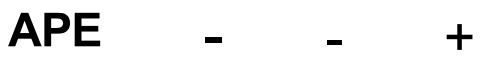

$\mathrm{H}_{2} \mathrm{O}_{2}++\quad+$

Figure 6. Centella extracts promote expression of antioxidant enzymes following $\mathrm{H}_{2} \mathrm{O}_{2}$ treatment. (A-D) In response to $\mathrm{H}_{2} \mathrm{O}_{2}$ treatment, $C A T$, GPX1 and $\mathrm{SOD} 1$ expressions were increased in CE-treated fibroblasts, while SOD2 transcription were elevated in APE-treated fibroblasts. BJ cells were incubated with CE $(60 \mu \mathrm{g} / \mathrm{mL} ; 24 \mathrm{~h})$ or APE $(60 \mu \mathrm{g} / \mathrm{mL} ; 24 \mathrm{~h})$, then exposed to $\mathrm{H}_{2} \mathrm{O}_{2}(200 \mu \mathrm{M} ; 1 \mathrm{~h})$. The transcriptional levels of CAT, GPx1, SOD1, and SOD2, were evaluated with RT-PCR following treatments $\left(n=3\right.$; mean \pm SEM; ${ }^{\dagger} P<0.05 \mathrm{vs}_{2} \mathrm{O}_{2}$-treated cells). 
Effects of Centella extracts on expression of matrix metalloprotease 9 (MMP-9). Matrix metalloprotease-9 (MMP-9) is the gelatinase enzyme that is responsible for regulation of homeostasis of collagen. Formation of oxidative stress can lead to upregulation of MMP-9 in fibroblasts, which subsequently results in degradation of collagen. The increased breakdown of collagen by MMP-9 appears to be the major factor for aging processes of skin tissue ${ }^{34,35}$. Here, we demonstrated that exposure to $\mathrm{H}_{2} \mathrm{O}_{2}$ markedly upregulated the expression level of MMP-9 of dermal fibroblasts (Fig. 7A). Elevation of MMP-9 expression was significantly suppressed by $\mathrm{CE}$ and APE pre-treatment (Fig. 7B). These data suggested that $\mathrm{CE}$ and APE may possess anti-aging activities via an inhibition of $M M P-9$ transcription.

\section{Discussions}

C. asiatica is a medicinal plant with broad range of pharmacological effects e.g. antioxidant ${ }^{8-11}$, anti-inflammation $^{36,37}$, wound healing ${ }^{38-40}$, neuroprotective ${ }^{8,9}$ and memory improvement ${ }^{41,42}$. Due to its high therapeutic potential, the demand for this plant in cosmeceutical and pharmaceutical industries has exceeded the supply from conventional cultivation. Callus culture offers a manufacturing system which ensures the continuous supply of compounds with uniform quality and high yields ${ }^{13}$. Here, we demonstrated that $50 \%$ ethanol is the suitable solvent to be used in extraction process for C. asiatica due to (i.) antioxidant activity of extracts; and (ii.) safety from reduced solvent residue. The $50 \%$ ethanolic extracts from callus culture has unique chemical profiles and biological activities. Compared to APE, the data from HPTLC (Fig. 1,2) and HPLC (Fig. 3) suggested that (1) $\mathrm{CE}$ comprises of unique antioxidant compounds which should be further identified; (2) the types of secondary metabolites in CE are different from APE. Interestingly, results from DPPH assay showed that the total antioxidant activity of CE is higher than APE (Supplementary Fig. 1). The greater antioxidant activity of CE is possibly due to the differences in active components in the extracts. We demonstrated that the major triterpenoids of C. asiatica (asiaticoside, asiaticoside, asiatic acid, madecassoside and madecassic acid) are not responsible for antioxidant activities of CE (Fig. 1). These findings are parallel to previous observation demonstrating that triterpene-free-extract of $C$. asiatica possesses greater in vitro radical scavenging properties as well as in vivo antioxidant activities than triterpene-enriched-extract. Triterpene-free-fraction of C. asiatica has significantly stronger in free-radical scavenging activities than triterpene-enriched-extract as determined by several in vitro anti-radical assays, including DPPH, ABTS, NORAC, ORAC and NO scavenging assays. Moreover, pre-treatment with triterpene-free-extract of $C$. asiatica reduced levels of malonaldehyde, an oxidative stress marker, in brain tissues of scopolamine-treated-rat, while triterpene-enriched-fraction did not have these protective effects ${ }^{43}$. These preclinical findings support our results that the centelloids are not principal contributors for antioxidant activity of C. asiatica.

Kaempferol, quercetin, and rutin have been reported to be major flavonoids with antioxidant properties of C. asiatica ${ }^{27,28}$. Our HPTLC-DPPH and HPLC results demonstrated that these flavonoids did not present in $50 \%$ ethanolic extracts from both callus culture and authentic plant; then these series of flavonoids did not contribute to antioxidant activities of these extracts (Fig. 2). Hence, future studies are required to identify and characterize novel antioxidants presented in these extracts.

The process of skin aging is closely associated with an induction of oxidative stress in dermal fibroblasts ${ }^{1}$. Hence, compound that can prevent oxidative damage in dermal fibroblasts could be a potential candidate to be used as anti-skin-aging in cosmeceutical product. We then further investigated biological activities of Centella extracts against oxidative stress on dermal fibroblasts. Our data from MTT assay as well as bioenergetic study showed that $\mathrm{CE}$ significantly inhibited the cytotoxicity of $\mathrm{H}_{2} \mathrm{O}_{2}$ on dermal fibroblasts (Fig. 4). The preventive effects of CE were comparable to APE. Moreover, we found that the protective activities of these extracts could be due to an increase in capacity of fibroblasts to eliminate ROS. We used RT-qPCR approach to investigate the alterations of mRNA expression of key antioxidant enzymes in response to treatments. Catalase is the major enzyme involved in the elimination of high fluxes of $\mathrm{H}_{2} \mathrm{O}_{2}$, while $\mathrm{GPx} 1$ is responsible for detoxification of low fluxes of $\mathrm{H}_{2} \mathrm{O}_{2}{ }^{44}$. SOD1 is a cytosolic $\mathrm{Cu} / \mathrm{Zn}$-superoxide dismutase, whereas SOD2 is a mitochondrial Mn-superoxide dismutase. Both SOD1 and SOD2 are crucial for removal of superoxide free radical $\left(\mathrm{O}_{2}^{-}\right)$during oxidative stress condition. The dismutation of $\mathrm{O}_{2}{ }^{--}$by SOD leads to generation of $\mathrm{H}_{2} \mathrm{O}_{2}$, which in turn eliminated by catalase and other peroxidases ${ }^{45}$. RT-qPCR data revealed that CE and APE have different downstream targets on cellular antioxidant machineries. Treatment with CE promoted mRNA expression of $\mathrm{H}_{2} \mathrm{O}_{2}$-detoxifying enzyme, CAT

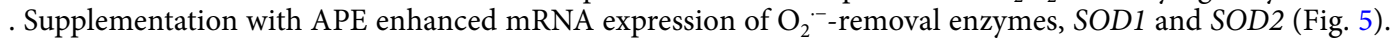
In response to $\mathrm{H}_{2} \mathrm{O}_{2}$ treatment, pre-exposure to CE induced CAT, GPX1 and SOD1 expression, whereas pretreatment with APE upregulated SOD2 expression (Fig. 6). Upregulation of these antioxidant machineries due to Centella extracts could promote capacity of fibroblasts to eliminate harmful ROS, resulting in suppression of oxidative damage and prevention of cell death. Further studies on protein levels and enzymatic activities of antioxidant machineries following treatments of CE and APE are necessary to better understand the protective mechanisms of these extracts on fibroblasts.

Consistent with our findings, many preclinical studies also demonstrated that the beneficial activity of Centella extracts against oxidative-stress-related-disorders could be due to an augmentation in expression and/or activity of cellular antioxidant enzymes. In rat model of hepatic injury, administration of Centella extract prevented hepatotoxicity through an increased level of catalase, SOD and GPx in liver tissues ${ }^{46}$. In hamster model of hyperlipidemia, supplementation with ethanolic extract of $C$. asiatica promote hepatic function by an enhanced expression of SOD and GPx in hepatic tissues ${ }^{47}$. In diabetic rat, aqueous extracts from C. asiatica ameliorate hippocampal dysfunction by an induction of catalase, SOD and GPx expression in hippocampus ${ }^{48}$. In stroke model, supplementation with ethanolic extract of $C$. asiatica prevented brain injury through a restoration of glutathione level and augmentation of catalase, SOD and GPx activities in ischemic rat ${ }^{49}$. Taken together, these 

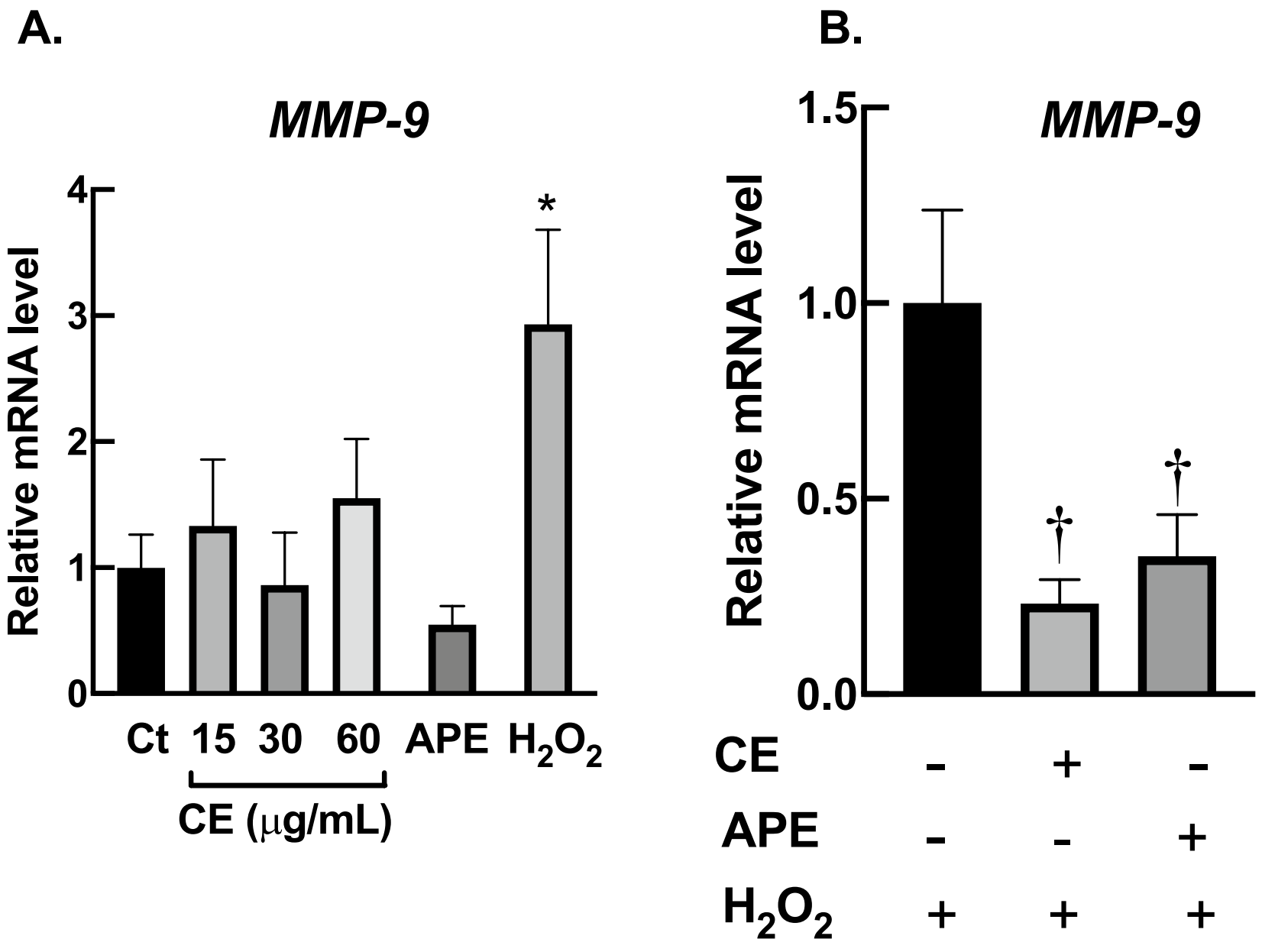

Figure 7. Centella extracts inhibit expression of $M M P 9$ following $\mathrm{H}_{2} \mathrm{O}_{2}$ treatment. (A) Exposure to $\mathrm{H}_{2} \mathrm{O}_{2}$ resulted in elevation of $M M P 9$ expression, while $\mathrm{CE}$ and APE did not affect the transcription of $M M P 9$. BJ cells were treated CE $(15-60 \mu \mathrm{g} / \mathrm{mL} ; 24 \mathrm{~h})$ or APE $(60 \mu \mathrm{g} / \mathrm{mL} ; 24 \mathrm{~h})$ or $\mathrm{H}_{2} \mathrm{O}_{2}(200 \mu \mathrm{M} ; 1 \mathrm{~h})$. (B) CE and APE suppressed $\mathrm{H}_{2} \mathrm{O}_{2}$-induced $M M P 9$ expression. BJ cells were pre-incubated with CE or APE $(60 \mu \mathrm{g} / \mathrm{mL})$ for $24 \mathrm{~h}$ then exposed to $\mathrm{H}_{2} \mathrm{O}_{2}(200 \mu \mathrm{M})$ for $1 \mathrm{~h}$. The transcriptional levels of $M M P 9$ were evaluated with RT-PCR following treatments $\left(n=3\right.$; mean \pm SEM; ${ }^{\star} P<0.05$ vs untreated control; ${ }^{\dagger} P<0.05 \mathrm{vs} \mathrm{H}_{2} \mathrm{O}_{2}$-treated cells).

previous observations strongly support our RT-QPCR results which demonstrating that $50 \%$ ethanolic extracts of Centella inhibited oxidative damage on human dermal fibroblasts via an upregulation of antioxidant enzymes.

The nuclear factor erythroid 2-related factor (Nrf2)/ antioxidant response element (ARE) pathway is an essential signaling network that maintains redox homeostasis for human cells ${ }^{50}$. Nrf2 functions as a redox sensor for oxidative stress. In the presence of oxidative insults, Nrf2 translocates into nucleus and binds to promoter regions of ARE, leading to transcriptional activation of a battery of cytoprotective and detoxification genes, including CAT, GPX and SOD ${ }^{51-54}$. Activation of Nrf2/ARE pathway by Centella extracts has been observed in preclinical models of oxidative-stress-related disease. A water extract of Centella asiatica can attenuate oxidative stress and activate Nrf2/ARE network in isolated primary neurons and rodent models of pathological cognitive impairment. The activation of this pathway by Centella extract is strongly accompanied by an improvement in neuronal health and cognitive function ${ }^{8,55-58}$. Recently, Park and colleagues demonstrated that pre-treatment with Centella extract can prevent the progression of age-related macular degeneration in vitro and in vivo. They clearly showed that the cytoprotective activities against oxidative damage of Centella extract in cell culture and animal experiment is mainly due to the regulation of $\mathrm{Nrf} 2$ pathway $^{59}$. Hence, we postulated that Nrf2/ARE pathway could be a potential mediator for the beneficial effects of Centella extracts in our model. Further pharmacological study is required to validate this hypothesis.

In addition to effects on cellular antioxidant enzymes, we also observed activities of Centella extracts on expression of MMP-9. MMP-9 is zinc-containing-gelatinase which plays an important role in degradation of dermal extracellular matrix, especially collagen type IV. Environmental insults, e.g. UV irradiation, tobacco smoke, and pollutants, have been reported to induce expression of $M M P-9$ of skin cells through formation of oxidative stress $^{35}$. Upregulation of MMP-9 leads to fragmentation of dermal collagen; thereby diminish skin elasticity and integrity; and eventually promote wrinkle and sagging formation of $\operatorname{skin}^{34,60}$. Hence, agents with MMP-9 


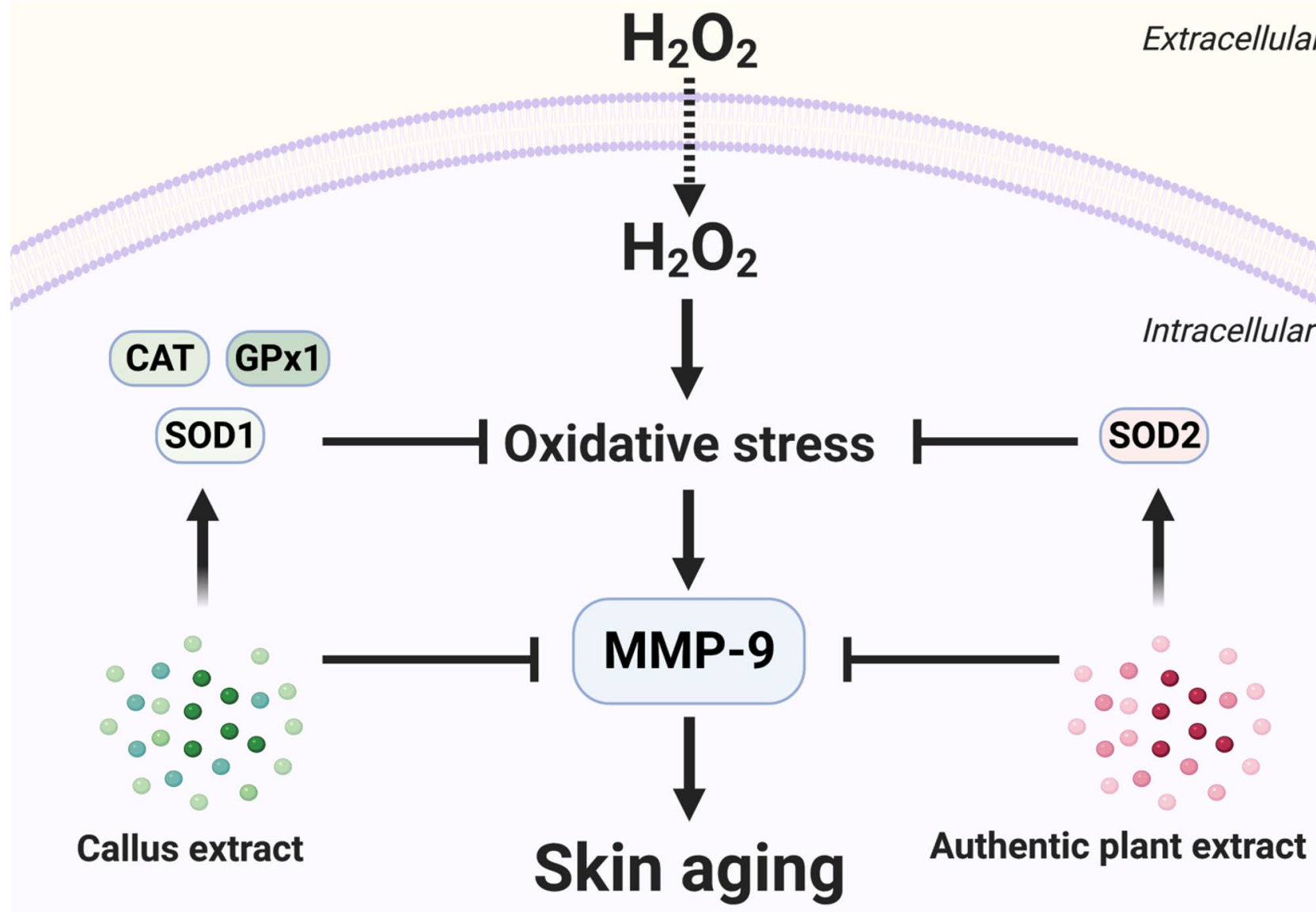

Figure 8. Proposed mechanisms for antioxidant and anti-skin aging activities of Centella extract. Pre-treatment with Centella extracts prevent $\mathrm{H}_{2} \mathrm{O}_{2}$-induced cytotoxicity on dermal fibroblasts by upregulation of cellular antioxidant machineries. Supplementation with CE upregulated CAT, GPXI and SOD1 expression, whereas pretreatment with APE induced SOD2 expression following $\mathrm{H}_{2} \mathrm{O}_{2}$ treatment. Moreover, pre-treatment with CE or APE suppressed $\mathrm{H}_{2} \mathrm{O}_{2}$-mediated-upregulation of $M M P$-9. This figure was created with BioRender.com.

inhibitory activities would be an attractive candidate to combat skin aging ${ }^{61}$. Our RT-qPCR data demonstrated that CE and APE significantly inhibited upregulation of $M M P 9$ following $\mathrm{H}_{2} \mathrm{O}_{2}$ exposure (Fig. 7), suggesting anti-skin-aging activities of these extracts. Future observations on detailed mechanisms of CE/APE-mediated$M M P 9-e x p r e s s i o n$ are required to better understand their anti-skin-aging effects. The proposed mechanisms for antioxidant and anti-skin aging activities of CE and APE are summarized in Fig. 8.

In conclusion, our present study provides the potential application of callus culture platform to produce biomass and biochemical from C. asiatica. We demonstrated that the $50 \%$ ethanolic extract from callus culture has unique chemical profiles and distinct antioxidant properties. Moreover, this study provides pharmacological evidence to support the use of Centella extracts as anti-skin-aging agents in cosmeceutical and pharmaceutical products.

Received: 7 February 2021; Accepted: 18 June 2021

Published online: 29 June 2021

\section{References}

1. Rinnerthaler, M., Bischof, J., Streubel, M. K., Trost, A. \& Richter, K. Oxidative stress in aging human skin. Biomolecules 5, 545-589. https://doi.org/10.3390/biom5020545 (2015).

2. Fisher, G. J. et al. Collagen fragmentation promotes oxidative stress and elevates matrix metalloproteinase-1 in fibroblasts in aged human skin. Am. J. Pathol. 174, 101-114. https://doi.org/10.2353/ajpath.2009.080599 (2009).

3. Shin, J. W. et al. Molecular mechanisms of dermal aging and antiaging approaches. Int. J. Mol. Sci. 20, 2126. https://doi.org/10. 3390/ijms20092126 (2019).

4. Morita, A. Tobacco smoke causes premature skin aging. J. Dermatol. Sci. 48, 169-175. https://doi.org/10.1016/j.jdermsci.2007.06. 015 (2007).

5. Parrado, C. et al. Environmental stressors on skin aging. Mechanistic insights. Front. Pharmacol. 10, 759. https://doi.org/10.3389/ fphar.2019.00759 (2019).

6. Tu, Y. \& Quan, T. Oxidative stress and human skin connective tissue aging. Cosmetics 3, 28 (2016). 
7. Sun, B. et al. Therapeutic potential of Centella asiatica and its triterpenes: A review. Front. Pharmacol. 11, 568032. https://doi.org/ 10.3389/fphar.2020.568032 (2020).

8. Gray, N. E. et al. Centella asiatica attenuates mitochondrial dysfunction and oxidative stress in A $\beta$-exposed hippocampal neurons. Oxid. Med. Cell Longev. 2017, 7023091. https://doi.org/10.1155/2017/7023091 (2017).

9. Bhatnagar, M., Goel, I., Roy, T., Shukla, S. D. \& Khurana, S. Complete comparison display (CCD) evaluation of ethanol extracts of Centella asiatica and Withania somnifera shows that they can non-synergistically ameliorate biochemical and behavioural damages in MPTP induced Parkinson's model of mice. PLoS One 12, e0177254. https://doi.org/10.1371/journal.pone.0177254 (2017).

10. Kumari, S., Deori, M., Elancheran, R., Kotoky, J. \& Devi, R. In vitro and In vivo antioxidant, anti-hyperlipidemic properties and chemical characterization of Centella asiatica (L.) extract. Front. Pharmacol. 7, 400. https://doi.org/10.3389/fphar.2016.00400 (2016).

11. Intararuchikul, T. et al. Effects of Centella asiatica extract on antioxidant status and liver metabolome of rotenone-treated rats using GC-MS. Biomed. Chromatogr. 33, e4395. https://doi.org/10.1002/bmc.4395 (2019).

12. Yang, L. et al. Response of plant secondary metabolites to environmental factors. Molecules 23, 762. https://doi.org/10.3390/molec ules23040762 (2018).

13. Efferth, T. Biotechnology applications of plant callus cultures. Engineering 5, 50-59. https://doi.org/10.1016/j.eng.2018.11.006 (2019).

14. Gamborg, O. L. \& Phillips, G. C. In Plant Cell, Tissue and Organ Culture: Fundamental Methods (eds Gamborg, O. L. \& Phillips, G. C.) 35-42 (Springer, Berlin, 1995)

15. Loc, N. H. \& An, N. T. T. Asiaticoside production from centella (Centella asiatica L. Urban) cell culture. Biotechnol. Bioprocess. E 15, 1065-1070. https://doi.org/10.1007/s12257-010-0061-8 (2010).

16. HPTLC Association. Centella asiatica. https://www.hptlc-association.org/methods/methods.cfm (Accessed on 03/06/2021).

17. Ayoola-Oresanya, I. O. et al. Effect-directed profiling and identification of bioactive metabolites from field, in vitro-grown and acclimatized Musa spp. accessions using high-performance thin-layer chromatography-mass spectrometry. J. Chromatogr. A 1616, 460774. https://doi.org/10.1016/j.chroma.2019.460774 (2020).

18. Cheng, Z., Moore, J. \& Yu, L. High-throughput relative DPPH radical scavenging capacity assay. J. Agric. Food Chem. 54, 7429-7436. https://doi.org/10.1021/jf0611668 (2006).

19. Buraphaka, H. \& Putalun, W. Stimulation of health-promoting triterpenoids accumulation in Centella asiatica (L.) Urban leaves triggered by postharvest application of methyl jasmonate and salicylic acid elicitors. Ind. Crops Prod. 146, 112171. https://doi.org/ 10.1016/j.indcrop.2020.112171 (2020).

20. Schäuble, S. et al. Quantitative model of cell cycle arrest and cellular senescence in primary human fibroblasts. PLoS One 7, e42150-e42150. https://doi.org/10.1371/journal.pone.0042150 (2012).

21. Warinhomhoun, S. et al. Antioxidant activities and protective effects of dendropachol, a new bisbibenzyl compound from Dendrobium pachyglossum, on hydrogen peroxide-induced oxidative stress in HaCaT keratinocytes. Antioxidants (Basel) 10, 252. https:// doi.org/10.3390/antiox10020252 (2021).

22. Rani, D., Buranasudja, V., Kobtrakul, K., De-Eknamkul, W. \& Vimolmangkang, S. Elicitation of Pueraria candollei var. mirifica suspension cells promises antioxidant potential, implying antiaging activity. Plant Cell Tissue Organ. Cult. 145, 29-41. https://doi. org/10.1007/s11240-020-01990-4 (2021).

23. Rai, Y. et al. Mitochondrial biogenesis and metabolic hyperactivation limits the application of MTT assay in the estimation of radiation induced growth inhibition. Sci. Rep. 8, 1531. https://doi.org/10.1038/s41598-018-19930-w (2018).

24. Buranasudja, V. et al. Pharmacologic ascorbate primes pancreatic cancer cells for death by rewiring cellular energetics and inducing DNA damage. Mol. Cancer Res. 17, 2102-2114. https://doi.org/10.1158/1541-7786.Mcr-19-0381 (2019).

25. Biagini, F. et al. A novel 3D in vitro model of the human gut microbiota. Sci. Rep. 10, 21499. https://doi.org/10.1038/s41598-02078591-w (2020).

26. Wang, C., Zhao, Y., Yang, R. \& Liu, H. Simultaneous analysis of five triterpenes in Centella asiatica by high performance liquid chromatography with cyclodextrins as the mobile phase additives. Sci. Rep. 10, 18577. https://doi.org/10.1038/s41598-020-75554-z (2020).

27. Alqahtani, A. et al. Seasonal variation of triterpenes and phenolic compounds in Australian Centella asiatica (L.) Urb. Phytochem. Anal. 26, 436-443. https://doi.org/10.1002/pca.2578 (2015).

28. Mohammad Azmin, S. N. H. \& Mat Nor, M. S. Chemical fingerprint of Centella Asiatica's bioactive compounds in the ethanolic and aqueous extracts. Adv. Biomark. Sci. Technol. 2, 35-44. https://doi.org/10.1016/j.abst.2020.10.001 (2020).

29. Masaki, H. Role of antioxidants in the skin: Anti-aging effects. J. Dermatol. Sci. 58, 85-90. https://doi.org/10.1016/j.jdermsci.2010. $03.003(2010)$

30. Sreedhar, A., Aguilera-Aguirre, L. \& Singh, K. K. Mitochondria in skin health, aging, and disease. Cell Death Dis. 11, 444. https:// doi.org/10.1038/s41419-020-2649-z (2020).

31. Meewes, C. et al. Adaptive antioxidant response protects dermal fibroblasts from UVA-induced phototoxicity. Free Radic. Biol. Med. 30, 238-247. https://doi.org/10.1016/s0891-5849(00)00463-9 (2001).

32. Poswig, A. et al. Adaptive antioxidant response of manganese-superoxide dismutase following repetitive UVA irradiation. J. Invest. Dermatol. 112, 13-18. https://doi.org/10.1046/j.1523-1747.1999.00465.x (1999).

33. Wenk, J. et al. Stable overexpression of manganese superoxide dismutase in mitochondria identifies hydrogen peroxide as a major oxidant in the AP-1-mediated induction of matrix-degrading metalloprotease-1. J. Biol. Chem. 274, 25869-25876. https://doi.org/ $10.1074 /$ jbc.274.36.25869 (1999).

34. Pittayapruek, P., Meephansan, J., Prapapan, O., Komine, M. \& Ohtsuki, M. Role of matrix metalloproteinases in photoaging and photocarcinogenesis. Int. J. Mol. Sci. 17, 868. https://doi.org/10.3390/ijms17060868 (2016).

35. Fussell, J. C. \& Kelly, F. J. Oxidative contribution of air pollution to extrinsic skin ageing. Free Radic. Biol. Med. 151, 111-122. https://doi.org/10.1016/j.freeradbiomed.2019.11.038 (2020).

36. Park, J. H. et al. Anti-inflammatory effect of titrated extract of Centella asiatica in phthalic anhydride-induced allergic dermatitis animal model. Int. J. Mol. Sci. 18, 738. https://doi.org/10.3390/ijms18040738 (2017).

37. Hafiz, Z. Z. et al. Inhibitory effects of raw-extract Centella asiatica (RECA) on acetylcholinesterase, inflammations, and oxidative stress activities via in vitro and in vivo. Molecules 25, 892. https://doi.org/10.3390/molecules25040892 (2020).

38. Somboonwong, J., Kankaisre, M., Tantisira, B. \& Tantisira, M. H. Wound healing activities of different extracts of Centella asiatica in incision and burn wound models: an experimental animal study. BMC Complement. Altern. Med. 12, 103. https://doi.org/10. $1186 / 1472-6882-12-103(2012)$

39. Sh Ahmed, A. et al. Pharmacological properties of Centella asiatica hydrogel in accelerating wound healing in rabbits. BMC Complement. Altern. Med. 19, 213. https://doi.org/10.1186/s12906-019-2625-2 (2019).

40. Wu, F. et al. Identification of major active ingredients responsible for burn wound healing of Centella asiatica herbs. Evid Based Complement. Altern. Med. 2012, 848093. https://doi.org/10.1155/2012/848093 (2012).

41. Soumyanath, A. et al. Centella asiatica extract improves behavioral deficits in a mouse model of Alzheimer's disease: Investigation of a possible mechanism of action. Int. J. Alzheimer Dis. 2012, 381974. https://doi.org/10.1155/2012/381974 (2012).

42. Veerendra Kumar, M. H. \& Gupta, Y. K. Effect of Centella asiatica on cognition and oxidative stress in an intracerebroventricular streptozotocin model of Alzheimer's disease in rats. Clin. Exp. Pharmacol. Physiol. 30, 336-342. https://doi.org/10.1046/j.14401681.2003.03842.x (2003). 
43. Arora, R., Kumar, R., Agarwal, A., Reeta, K. H. \& Gupta, Y. K. Comparison of three different extracts of Centella asiatica for antiamnesic, antioxidant and anticholinergic activities: in vitro and in vivo study. Biomed. Pharmacother. 105, 1344-1352. https://doi. org/10.1016/j.biopha.2018.05.156 (2018).

44. Doskey, C. M. et al. Tumor cells have decreased ability to metabolize $\mathrm{H}_{2} \mathrm{O}_{2}:$ Implications for pharmacological ascorbate in cancer therapy. Redox Biol. 10, 274-284. https://doi.org/10.1016/j.redox.2016.10.010 (2016).

45. Fukai, T. \& Ushio-Fukai, M. Superoxide dismutases: Role in redox signaling, vascular function, and diseases. Antioxid. Redox Signal 15, 1583-1606. https://doi.org/10.1089/ars.2011.3999 (2011).

46. Choi, M. J. et al. Protective effects of Centella asiatica leaf extract on dimethylnitrosamine-induced liver injury in rats. Mol. Med. Rep. 14, 4521-4528. https://doi.org/10.3892/mmr.2016.5809 (2016).

47. Zhao, Y. et al. Effect of Centella asiatica on oxidative stress and lipid metabolism in hyperlipidemic animal models. Oxid. Med. Cell Longev. 2014, 154295. https://doi.org/10.1155/2014/154295 (2014).

48. Giribabu, N., Srinivasarao, N., Swapna Rekha, S., Muniandy, S. \& Salleh, N. Centella asiatica attenuates diabetes induced hippocampal changes in experimental diabetic rats. Evid. Based Complement. Altern. Med. 2014, 592062. https://doi.org/10.1155/ 2014/592062 (2014).

49. Tabassum, R. et al. Centella asiatica attenuates the neurobehavioral, neurochemical and histological changes in transient focal middle cerebral artery occlusion rats. Neurol. Sci. 34, 925-933. https://doi.org/10.1007/s10072-012-1163-1 (2013).

50. Yamamoto, M., Kensler, T. W. \& Motohashi, H. The KEAP1-NRF2 system: A thiol-based sensor-effector apparatus for maintaining redox homeostasis. Physiol. Rev. 98, 1169-1203. https://doi.org/10.1152/physrev.00023.2017 (2018).

51. Dreger, H. et al. Nrf2-dependent upregulation of antioxidative enzymes: A novel pathway for proteasome inhibitor-mediated cardioprotection. Cardiovasc. Res. 83, 354-361. https://doi.org/10.1093/cvr/cvp107 (2009).

52. Bajpai, V. K. et al. Antioxidant efficacy and the upregulation of Nrf2-mediated HO-1 expression by (+)-lariciresinol, a lignan isolated from Rubia philippinensis, through the activation of p38. Sci. Rep. 7, 46035. https://doi.org/10.1038/srep46035 (2017).

53. Miller, C. J. et al. Disruption of Nrf2/ARE signaling impairs antioxidant mechanisms and promotes cell degradation pathways in aged skeletal muscle. Biochim. Biophys. Acta Mol. Basis Dis. 1038-1050, 2012. https://doi.org/10.1016/j.bbadis.2012.02.007 (1822).

54. Kubo, E., Chhunchha, B., Singh, P., Sasaki, H. \& Singh, D. P. Sulforaphane reactivates cellular antioxidant defense by inducing Nrf2/ ARE/Prdx6 activity during aging and oxidative stress. Sci. Rep. 7, 14130. https://doi.org/10.1038/s41598-017-14520-8 (2017).

55. Gray, N. E. et al. Centella asiatica increases hippocampal synaptic density and improves memory and executive function in aged mice. Brain Behav. 8, e01024-e01024. https://doi.org/10.1002/brb3.1024 (2018).

56. Gray, N. E. et al. Centella asiatica attenuates hippocampal mitochondrial dysfunction and improves memory and executive function in $\beta$-amyloid overexpressing mice. Mol. Cell Neurosci. 93, 1-9. https://doi.org/10.1016/j.mcn.2018.09.002 (2018).

57. Matthews, D. G. et al. Centella Asiatica improves memory and promotes antioxidative signaling in 5XFAD mice. Antioxidants 8 , 630. https://doi.org/10.3390/antiox8120630 (2019).

58. Zweig, J. A. et al. Prolonged treatment with Centella asiatica improves memory, reduces amyloid- $\beta$ pathology, and activates NRF2regulated antioxidant response pathway in 5xFAD Mice. J. Alzheimers Dis. https://doi.org/10.3233/jad-210271 (2021).

59. Park, D.-W., Lee, Y.-G., Jeong, Y.-J., Jeon, H. \& Kang, S.-C. Preventive effects against retinal degeneration by Centella asiatica extract (CA-HE50) and asiaticoside through apoptosis suppression by the Nrf2/HO-1 signaling pathway. Antioxidants 10, 613. https:// doi.org/10.3390/antiox10040613 (2021).

60. Lago, J. C. \& Puzzi, M. B. The effect of aging in primary human dermal fibroblasts. PLoS One 14, e0219165. https://doi.org/10. 1371/journal.pone.0219165 (2019).

61. Freitas-Rodríguez, S., Folgueras, A. R. \& López-Otín, C. The role of matrix metalloproteinases in aging: Tissue remodeling and beyond. Biochim Biophys Acta - Mol Cell Res 2015-2025, 2017. https://doi.org/10.1016/j.bbamcr.2017.05.007 (1864).

\section{Acknowledgements}

This research was supported by PMU-C of the Office of the National Higher Education Science Research and Innovation Policy Council, Thailand. D.R. was supported by the Rachadapisek Sompote Fund for Postdoctoral Fellowships from the Graduate School of Chulalongkorn University, Thailand. A.M. is a recipient of Postdoctoral fellowship from the Second Century Fund (C2F), Chulalongkorn University, Thailand.

\section{Author contributions}

V.B., D.R., A.M., K.K. and S.V. conceived and designed the experiments; D.R. and K.K. prepared extracts and performed HPTLC-DPPH, DPPH and HPLC; V.B. performed MTT, bioenergetics and RT-qPCR study; A.M. conducted RT-qPCR study; V.B., D.R., A.M., and K.K. analyzed the data under supervision of S.V.; V.B. wrote main manuscript. All authors have read, revised, and provided approval for final manuscript.

\section{Competing interests}

The authors declare no competing interests.

\section{Additional information}

Supplementary Information The online version contains supplementary material available at https://doi.org/ 10.1038/s41598-021-92958-7.

Correspondence and requests for materials should be addressed to S.V.

Reprints and permissions information is available at www.nature.com/reprints.

Publisher's note Springer Nature remains neutral with regard to jurisdictional claims in published maps and institutional affiliations. 
(c) (i) Open Access This article is licensed under a Creative Commons Attribution 4.0 International cc) License, which permits use, sharing, adaptation, distribution and reproduction in any medium or format, as long as you give appropriate credit to the original author(s) and the source, provide a link to the Creative Commons licence, and indicate if changes were made. The images or other third party material in this article are included in the article's Creative Commons licence, unless indicated otherwise in a credit line to the material. If material is not included in the article's Creative Commons licence and your intended use is not permitted by statutory regulation or exceeds the permitted use, you will need to obtain permission directly from the copyright holder. To view a copy of this licence, visit http://creativecommons.org/licenses/by/4.0/.

(C) The Author(s) 2021 